\title{
Eighty years of CIRM. A journey of commitment and dedication in providing maritime medical assistance
}

\author{
Syed Sarosh Mahdi ${ }^{1}$, Francesco Amenta ${ }^{1,2}$ \\ ${ }^{1}$ Telemedicine and Telepharmacy Centre, University of Camerino, Camerino, Italy \\ ${ }^{2}$ Research Department, International Radio Medical Centre (CIRM), Rome, Italy
}

\begin{abstract}
Background: A review of activities of Centro Internazionale Radio Medico (International Radio Medical Centre, CIRM) from its foundation in 1935 until its $80^{\text {th }}$ anniversary in 2015 was accomplished. CIRM was founded in 1935 to provide medical assistance via radio to ships with no doctor on board and other distant patients who cannot be reached by a doctor. In 1950 CIRM was established as a non-profit-making foundation and has benefited since 1957 from an annual contribution from the Italian government.

Methods: Review of CIRM case histories and other published material from 1935 to 2015 and presenting them in a scientific yet simplified manner through the use of basic mathematical analysis. All the data was collected from CIRM's official archives in Rome.

Results and Conclusions: The results achieved by the Centre over 80 years include medical assistance to 81,016 patients on board ships (as well as on small islands and aircraft), with more than 500,000 medical messages received and transmitted. CIRM from its inception was organised into a medical service, a telecommunications service and a studies section. In 2002 the Centre was recognised as the Italian Telemedical Maritime Assistance Service (TMAS). In the 2010 the Centre was reorganised as a structure articulated in 4 departments, namely maritime telemedicine, telecommunication, research and occupational medicine. This was achieved to cover the different activities related to comprehensive health protection of seafarers. The 24-h continuous medical service is provided by doctors at the CIRM headquarters. The doctor on duty gives instructions for managing the case and continues to follow the patient with subsequent appointments until recovery or landing. In case of emergencies CIRM co-ordinates the transfer of patients assisted on board ships to a hospital ashore. CIRM has developed innovative approaches for the treatment of diseases and accidents on board of seagoing vessels by introducing standard telemedicine equipment on board ships, allowing the transmission of biomedical data from ships to the Centre. These new solutions are aimed at bringing a significant improvement of medical care for seafarers.
\end{abstract}

(Int Marit Health 2016; 67, 4: 187-195)

Key words: International Radio Medical Centre (CIRM), maritime health, telemedicine, occupational health, assistance, Telemedical Maritime Assistance Service (TMAS), history

\section{INTRODUCTION}

\section{HISTORY}

The International Radiomedical Centre (Centro Internazionale Radio Medico, CIRM) was established in 1935 with the aim of giving free radio medical advice to ships of all nationalities navigating on international waters. The Centre has its headquarters in Rome and its basic medical services are free of charge. Requests for medical advice reaching CIRM are handled by doctors who are on $24 \mathrm{~h}$ duty [1, 2].

Prof. Francesco Amenta, School of Medicinal and Health Products Sciences, University of Camerino, Via Madonna delle Carceri, 9, 62032 Camerino (MC),
tel: +39-0737403311, fax: +39-0737403325, e-mail: francesco.amenta@unicam.it

Paper presented at the Meeting “The Way Forward of Maritime Telemedicine" held in Rome on October, 30-31 2015 that was held on the occasion of celebration of the $80^{\text {th }}$ anniversary of Centro Internazionale Radio Medico (CIRM). 
The first license for radio medical service to ships was issued on November 18, 1920 to the Seamen's Church Institute on New York. From 1920s to 1930s several maritime countries developed radio medical facilities for their own fleets, with Sweden starting its radio medical Centre in 1922, Netherlands in 1930 and Germany in 1931 [3]. The first experience of enlargement of radio medical assistance from a domestic into an international organisation occurred in Italy in 1935, with the constitution of the CIRM. The Centre was chaired by Guglielmo Marconi and developed as a basic of medical organisation assisted by a physician, Prof. Guido Guida. CIRM was established with the mission of providing medical assistance via radio for sick or injured seafarers of any nationality, navigating in any part of the world [1, 2, 4, 5]. Over the years, CIRM has pursued its work, interrupted only during the war years 1941-1945, and has enlarged its activity to include patients aboard planes in flight and on small Italian islands. CIRM, a private association until 1950, and from that year established as a non-profit foundation, has benefited since 1957 from yearly contribution from the Italian government [1, 2, 4].

The Centre initially broadcasted an outpatient radio service, at certain times of day, in which a doctor was available to respond to requests for assistance, both for new cases, and for patients under treatment. Today CIRM is housed in a functional building in the EUR district of Rome (Fig. 1), designed to accommodate the Centre and adapted in order to be more responsive to the needs of the virtual hospital of CIRM. The activities of CIRM are coordinated by a President and a Board of Directors, which provide, among other things, the appointment of the President. The operational structures of CIRM until 2010 consisted of 3 specialised departments (telemedicine, telecommunications, studies and research), the coordination of the activities of which, in the absence of an employee who is responsible for it, is delegated to a member of the Board of Trustees. An Executive Committee and a Scientific-Ethical Committee collaborate with the President and the Board of Directors in promoting initiatives in the relevant fields of the Centre [1, 2, 4].

In 2002 the CIRM, by joint decree of the Italian Ministry of Infrastructure and Transport and the Minister of Health, the Centre was formally designated as the Italian Telemedical Maritime Assistance Service (TMAS), in accordance with Circular no. 960 dated June 20, 2000 of the International Maritime Organisation (IMO) [6]. Regulations establish that these activities should be done in close coordination and collaboration with the Italian Maritime Rescue and Coordination Centre (IMRCC) identified in Italy in the General Command of the Coast Guard. This designation recognised for the efficiency of CIRM service in the field of medical care, and the role of the Centre in ensuring safety and protection of human life at sea.

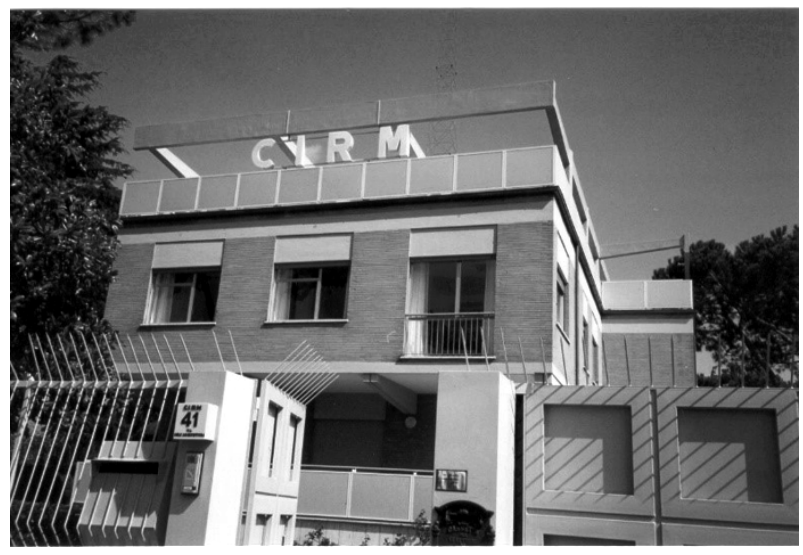

Figure 1. Current establishment of CIRM in EUR District of Rome

\section{CURRENT STRUCTURE AND ACTIVITIES}

In the 2010 the Centre was reorganised as a structure articulated in 4 departments, namely maritime telemedicine, telecommunication, research and occupational medicine. This to cover the different activities related to the global protection of the health of seafarers.

As part of the departmental organisation CIRM, the Department of Maritime Telemedicine is appointed to ensure the medical assistance activities of the Centre. In particular, the Department:

1) Provides advice and medical care. Medical advice includes the diagnosis and treatment of a disease on board;

2) Suggests the transfer of sick or traumatised sailors to the nearest port (MEDEVAC);

3) Liaising with medical organisations on the ground in the case of transhipment or hijacking.

The medical service, of which is responsible a medical director, is attended to by a variable number of doctors who are placed in an on call $24 \mathrm{~h}$ continuous service. The doctor on duty receives the request message from the ship and provides appropriate instructions, making appointments, more or less close together, depending on the severity of the disease to treat. The request for assistance can be sent by e-mail, phone, or other telecommunication systems, in Italian or English. If necessary, the doctor on duty may benefit from the advice of consultants, specialists in various branches of medicine, which are available in the case of complicated cases or health problems requiring a particular specialisation [1, 2, 4, 5, 7]. Depending on the severity of the case and the position of the vessel, which is periodically updated by the route, the captain of the ship can be advised to make diversions to the planned route in order to ensure immediate medical attention for a seriously ill patient. In an emergency on board in relation to the ship's position, patient transfer is coordinated through naval or air rescue 
missions. These missions are organised, in the case of seriously ill, near the Italian coast, with the collaboration of the IMRCC, while in foreign waters, they are organised in collaboration with the IMRCC of the various countries of the world $[1,2,4,5,7]$.

The patient is followed up with subsequent radio contact until the healing or landing. The on-board controls are urged to transmit to CIRM the diagnosis of the doctors who examined the patient. This diagnosis, in most cases, corresponds to that formulated at a distance from CIRM. In giving medical care, the medical team of CIRM takes into account the different provisions of medicines and medical devices available on board (the so-called medicine chests), which vary according to the nationality of the ship and the shipping company. Unfortunately, the lack of uniformity of the laws of the various countries can create problems for patients embarked on ships with limited availability of drugs or other medical devices.

Every day the medical team updates the statistics on health care. The diseases are divided into assisted nosological groups using the International Statistical Classification of Diseases and Related Health Problems (10 ${ }^{\text {th }}$ Revision) of the World Health Organisation (WHO) [8]. This can be helpful in conducting retrospective studies on specific diseases that are easily comparable with data for the general population.

The Department of Telecommunications is responsible for maintaining contact between the vessel/aircraft and the medical team of CIRM. The service, which works in the headquarter of the Centre uses the most modern information and communication tools and consists of a supervisor and telemedicine operators (called telemedicine assistants), which alternate in continuous duty to ensure 24-h coverage. Telemedicine assistants:

1) Manage the service of sending and receiving of medical messages from ships at sea, fishing boats, pleasure boats or airplanes;

2) With regard to their own share of responsibility, in close collaboration with the attending physicians, of the electronic compilation of medical records of each patient and updating the records after each teleconsultation. The communication systems used by CIRM are:

- E-mail, via an ADSL connection at high speed. The system most commonly used today as the forwarding rate of the message is much lower compared to Telex. Thanks to e-mail service, ships can send patient photographs as an attachment, which is of great help for diagnosis and therapy. The main service providers are represented by Telemar via the ground station of French Telecom, and with Globe Wireless.

- Telephone for all requests for telephony, which are recorded using an electronic recording system;

- Coastal radio stations.
In the past, the Centre had its own coastal radio station in telegraphy, which has maintained, throughout its existence, the distinction of being the only radio station in the world to carry out solely medical service. With the technological advancements of recent years most of the old radio communication systems have been replaced by modern information systems that enable fast, reliable telecommunications from all corners of the planet. The improvement of telecommunication systems has also fostered a steady increase, observed in recent years, of requests for assistance also from areas such as the Far East, which for geographical reasons, in the past, could communicate with Rome, but with great difficulty [1, 2, 4, 7].

The Research Department is involved in research activities primarily on seafarers' pathophysiology. Research activity of the Centre is relevant and CIRM was recognised officially in 2015 as a research Centre. Research activity of CIRM Research Department is performed independently or in collaboration with Italian or international universities or other research institutions. Research of CIRM is directed mainly towards 4 main areas, namely:

- Actions for improving medical care of seafarers;

- Inspections via telepharmacy, the ship's pharmacy and issuing of international compliance certificates;

- Collaboration for maintenance of high hygiene standards on board ships;

- Improvement of health-related training of seafarers.

The Occupational Medicine Department is involved in the development and practice of the project named Healthy Ship. Healthy Ship is a project for providing global health protection of seafarers on board ships. The project follows the legal obligation relating to the "compulsory health information for workers destined overseas", which is specifically governed by Italian Legislative Decree 271/1999 [9] and subsequent amendments.

Phases of the project Healthy Ship include:

1) Health education;

2) Psychological assessment of onboard employment and duty assignment;

3) Risk communication;

4) Risk management;

5) Health surveillance.

\section{CIRM MEDICAL ASSISTANCE}

Since the starting of CIRM activity on $6^{\text {th }}$ April 1935 until $31^{\text {st }}$ December, over a period of over 80 years, the Centre assisted 81,016 patients on ships, with over 500,000 medical messages being received and transmitted. Dozens of people were also assisted on small Italian islands or on board passenger aircraft (Table 1) [1, 2, 4, 5, 7, 10].

From the period of 2005-2015, CIRM received a total of 27,473 calls for medical assistance, the number of assis- 
Table 1. Number of patients assisted by CIRM on board ships and medical messages received and transmitted, 1935-2015

\begin{tabular}{llll}
\hline Years & Patients assisted & Average patients per year & $\begin{array}{l}\text { Teleconsultations } \\
\text { (medical messages) }\end{array}$ \\
\hline $1935-1940$ & 336 & 56 & 1,398 \\
$1946-1951$ & 1,069 & 178 & 6,858 \\
$1952-1956$ & 3,055 & 611 & 14,495 \\
$1957-1961$ & 5,116 & 1,023 & 40,360 \\
$1962-1966$ & 5,527 & 1,105 & 39,805 \\
$1967-1971$ & 7,096 & 1,419 & 55,375 \\
$1972-1976$ & 6,147 & 1,229 & 57,790 \\
$1977-1981$ & 4,681 & 936 & 47,185 \\
$1982-1986$ & 3,717 & 743 & 45,880 \\
$1987-1991$ & 3,498 & 700 & 36,850 \\
$1992-1995$ & 2,693 & 673 & 36,590 \\
$1995-2004$ & 10,608 & 1,060 & 52,278 \\
$2005-2010$ & 11,583 & 2,370 & 61,562 \\
$2011-2015$ & 15,890 & 2,747 & 64,316 \\
Total & 81,016 & & 560,742 \\
& & &
\end{tabular}

Table 2. Life threatening conditions for which CIRM received more often requests for medical advice

\begin{tabular}{|c|c|c|c|c|c|c|c|}
\hline Year & Total cases & 1 & 2 & 3 & 4 & 5 & 6 \\
\hline 2005 & 1,593 & 7 & 66 & 82 & 48 & 5 & 1 \\
\hline 2006 & 1,643 & 21 & 68 & 78 & 50 & 2 & 0 \\
\hline 2007 & 1,813 & 16 & 97 & 76 & 68 & 0 & 1 \\
\hline 2008 & 1,958 & 12 & 92 & 71 & 79 & 2 & 1 \\
\hline 2009 & 2,318 & 20 & 107 & 83 & 102 & 0 & 0 \\
\hline 2010 & 2,528 & 19 & 120 & 107 & 106 & 2 & 2 \\
\hline 2011 & 2,659 & 17 & 133 & 111 & 98 & 3 & 2 \\
\hline 2012 & 3,206 & 23 & 157 & 126 & 130 & 0 & 5 \\
\hline 2013 & 3,518 & 27 & 163 & 149 & 137 & 2 & 1 \\
\hline 2014 & 4,091 & 29 & 205 & 179 & 150 & 5 & 1 \\
\hline 2015 & 2,146 & 23 & 95 & 79 & 50 & 0 & 2 \\
\hline Total & 27,473 & $214(0.78 \%)$ & $1,303(4.74 \%)$ & 1,141 (4.15\%) & $1,018(3.70 \%)$ & $21(0.08 \%)$ & $16(0.06 \%)$ \\
\hline
\end{tabular}

1 - Loss of consciousness/convulsions; 2 - Serious accidents; 3 - Loss of blood; 4 - High fever; 5 - Serious respiratory problems; 6 - Serious diabetes complications

tance calls is going up each year, the majority of those are for common health problems that could be anything from viral respiratory infection to tooth pain [7]. There are also several life threatening conditions for which CIRM regularly receives calls of assistance from various ships. They have been summed up in Table 2 along with the most commonly reported life threatening conditions along with the total cases CIRM recorded and assisted from the year 2005-2015.

The mission envisioned by the founders of the Centre, that has governed the aims and objectives of CIRM from its inception was to provide medical assistance to seafarers of all nationalities in international waters. This feature differentiates CIRM from some other similar centres operating in different maritime countries, which limit their activity primarily to ships of their flag and/or vessels sailing in the vicinity of their national waters $[11,12]$. Figure 2 shows the nationality of ships requiring medical advice from CIRM from 2010 to 2014, divided into Italians and non-Italian vessels. As shown, the Centre provides the majority of its assistance to non-Italian flag ships.

An analysis of the trend of different groups of main pathologies assisted by CIRM over the years is detailed below. Analyses were performed starting from 1952 until 2015, 


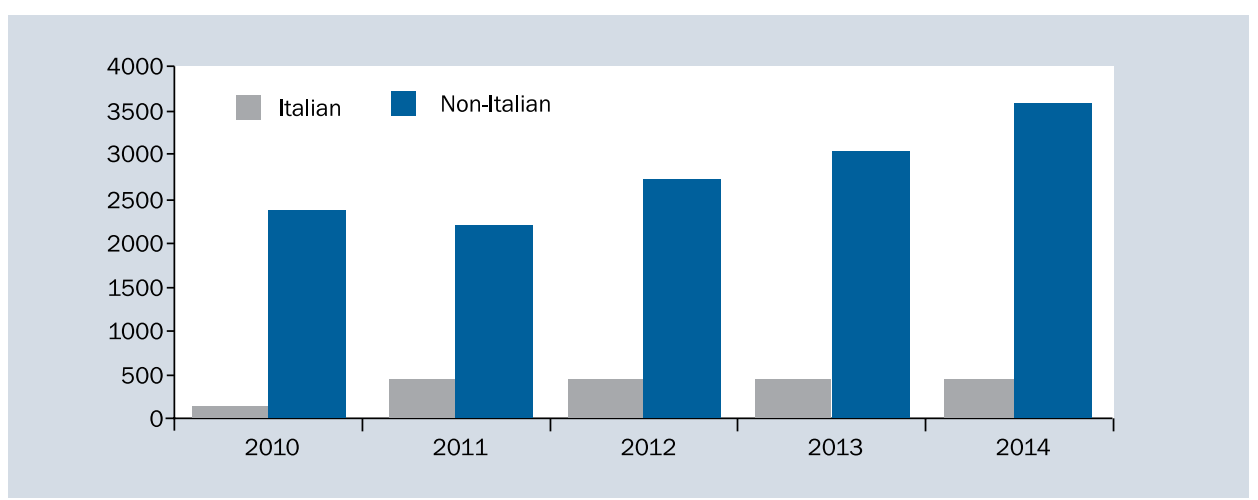

Figure 2. Requests for medical advice received by CIRM from Italian and non-Italian flag ships from 2010 to 2014

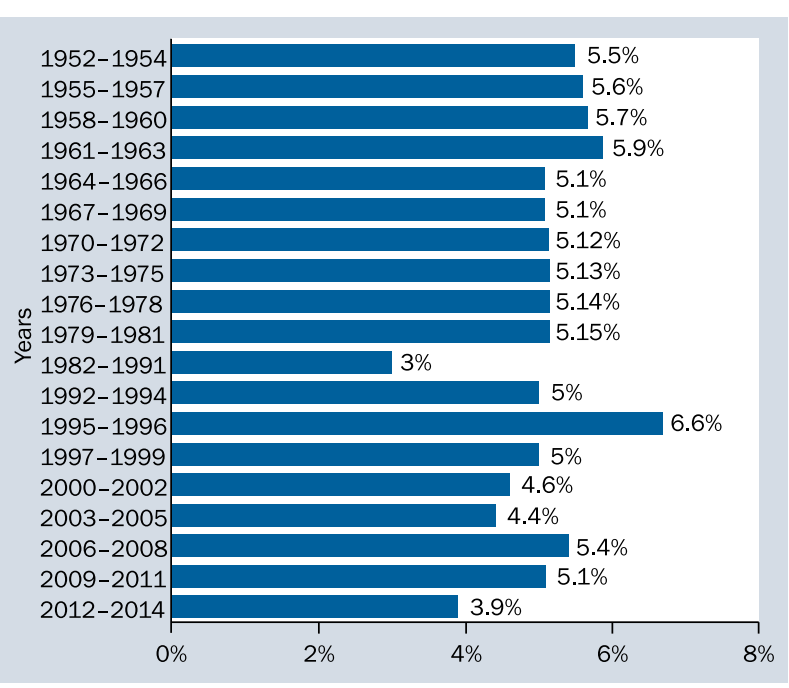

Figure 3. Infectious and parasitic diseases assisted by CIRM from 1952 to 2014. Data are expressed as the percentage of the total cases assisted by the Centre in the years of observation

depending on disease classification followed at the time.

Infectious and parasitic diseases. During the period 1952-1984 infectious and parasitic diseases ranged from $2 \%$ to $7 \%$ of the total diseases managed. From 1984 to 1994 these disease totalled around $5 \%$ of the total pathologies assisted by CIRM. A peak of these pathologies was noticeable in 1995-1996 (Fig. 3), followed by a gradual decrease. Infectious and parasitic diseases showed an upward trend from 2006 to 2011 (Fig. 3). It cannot be excluded that the recent increase of these diseases may be due to a greater antibiotic resistance noticeable in the last few years. In 2012-2014, 3.9\% of the diseases managed were due to infections (Fig. 3).

Diseases of the nervous system. Until 2007, CIRM followed the previous version of the WHO International Classification of Diseases, namely the ICD-9 [13]. According to this classification disease of the nervous system and sense organs were grouped together. This makes difficult

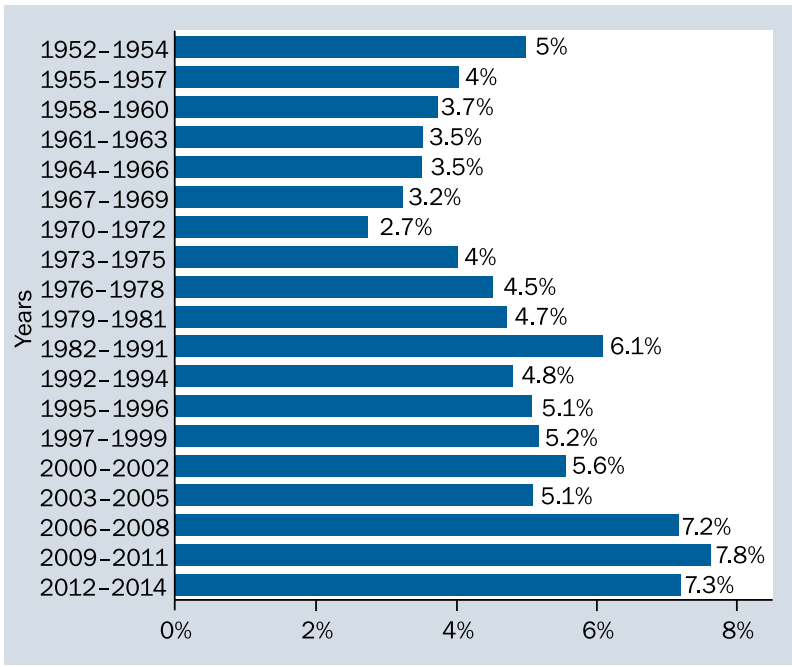

Figure 4. Diseases of the nervous system and organs of sense assisted by CIRM from 1952 to 2014. Data are expressed as the percentage of the total cases assisted by the Centre in the years of observation

comparison of the trend of nervous system and eye or ear pathologies along the years. From 1952 to 1972 these pathologies showed a reduction. An increase was noticeable from 1973 to 1982-1991, when these diseases reached the peak of the $6.1 \%$ (Fig. 4). From 2006 this group of pathologies averages more than the $7 \%$ of total pathologies assisted (Fig. 4). In 2014 the cases of nervous system and sense organs pathologies assisted were 300, with 116 cases of nervous system diseases (Bell's palsy, neuralgia, transient ischaemic attack, stroke) and 184 cases of sense organs diseases (mainly conjunctivitis, and otitis).

Diseases of the circulatory system. Cardiovascular diseases managed by CIRM have seen a steady increase since 1982 (Fig. 5). From the period of 1970-1975 only $2 \%$ of the total cases were due to cardiovascular diseases which jumped to $5 \%$ in the period from 1982 to 1984 . The most common cardiac complains were ischaemic disease and myocardial infarction. From 1992-1994 these cases 


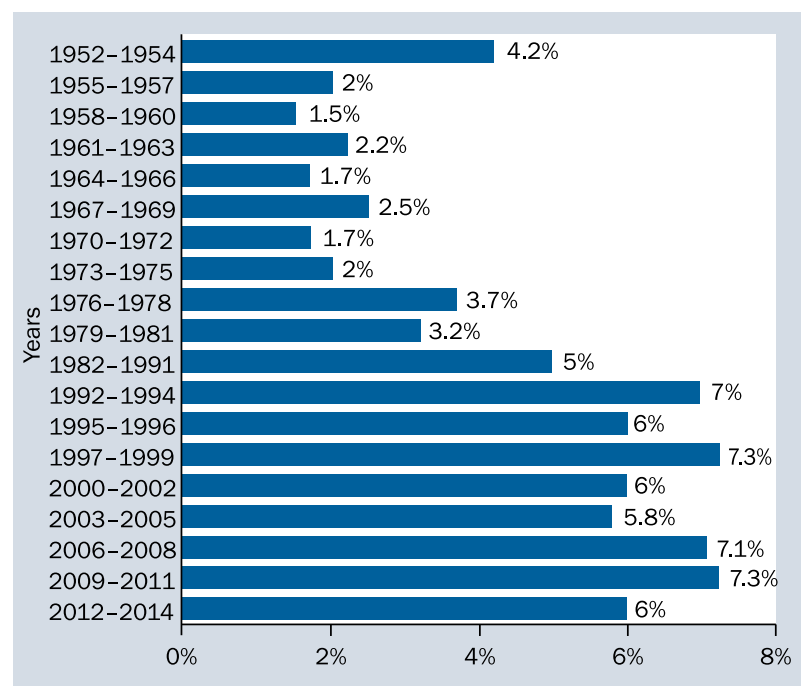

Figure 5. Diseases of the cardiovascular system assisted by CIRM from 1952 to 2014. Data are expressed as the percentage of the total cases assisted by the Centre in the years of observation

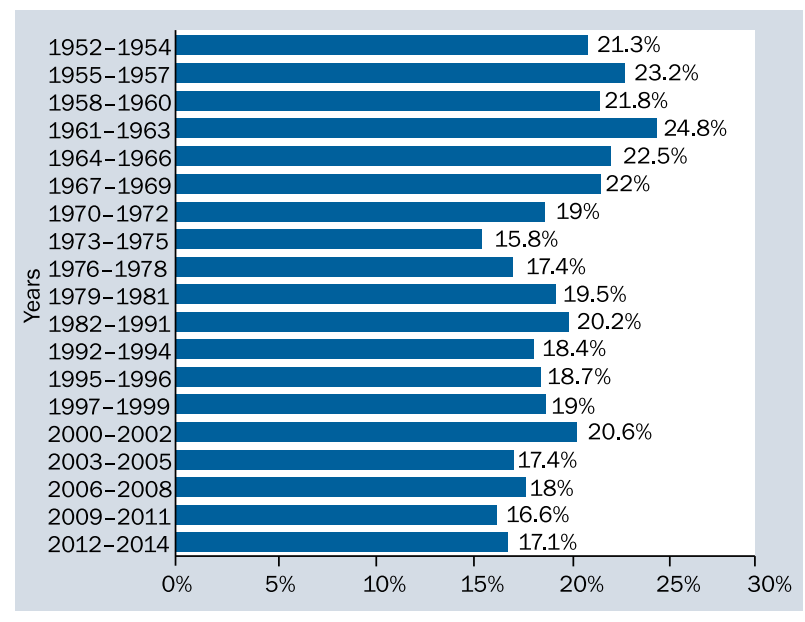

Figure 6. Diseases of the digestive system assisted by CIRM from 1952 to 2014. Data are expressed as the percentage of the total cases assisted by the Centre in the years of observation

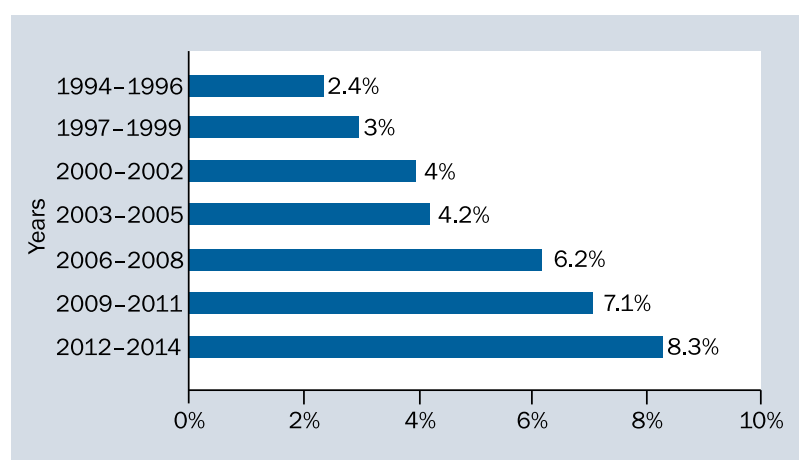

Figure 7. Diseases of the skin assisted by CIRM from 1994 to 2014. Data are expressed as the percentage of the total cases assisted by the Centre in the years of observation reached $7 \%$ of the total cases dropping marginally only in 2005 to $5.2 \%$ only to rise again from 2006-2009 in which cardiac cases accounted for $6.77 \%$ of all cases. In 2014 , CIRM treated 240 sailors with cardiac issues which is $6 \%$ of all cases treated that year (Fig. 5).

Cardiovascular diseases represented the first cause of death among seafarers assisted by CIRM [14].

Diseases of the respiratory system. Respiratory disease rates treated by CIRM have shown a very consistent rate. From the period of 1995-2004 the respiratory disease rates were $5.5 \%$ and in 2014, 184 cases of respiratory problems were treated at CIRM which represents $5.3 \%$ of all diseases treated (data not shown). The most common respiratory issues suffered by seafarers are asthma and bronchitis.

Diseases of the digestive system. From the period of 1952-1984 digestive tract pathologies were the number one cause of referral to CIRM (Fig. 6). During the period of $1952-1961,22 \%$ of all diseases treated by the organisation were digestive issues. The trend declined slightly from $1973-1975$ to $16.8 \%$ only to increase from $1982-1991$ to $20 \%$ (Fig. 6). The most frequent digestive tract ailments suffered by seafarers are gastritis, colitis, ulcers and gallstones. The rates remained more or less same between 1995 and 2014 and with better hygiene and treatment options, digestive tract diseases accounted for $17 \%$ of all the cases treated by CIRM in 2014. More recently, CIRM has also started collecting data for dental problems faced by a seafarers and a new program to deal with dental hygiene has commenced under supervision of a dentist [15, 16].

Diseases of the skin and subcutaneous tissue. Data on diseases of the skin and subcutaneous tissue were collected from 1994 (Fig. 7). Prevalence of dermatological ailments averaged $3.7 \%$ in 2005 to reach the $8.3 \%$ of total cases assisted in 2012-2014 (Fig. 7). Diagnosis and treatment of dermatological problems on board is today much easier compared to the past as pictures attached to e-mail messages of request for medical advice are in general send to the CIRM. In these specific cases pictures help much more of the otherwise limited and imprecise description can be obtained from a ship's captain or his delegate.

Diseases of the musculo-skeletal system. Similarly, as mentioned above regarding diseases of the skin, data on pathologies of the locomotor system were also collected only since 1994 . At the beginning the incidence of these diseases was limited, whereas in 2014 we had 249 cases (6.14\%) of musculoskeletal pathologies (Fig. 8).

Diseases of the genitourinary system. From 1952-1957 genitourinary diseases represented the $8 \%$ of the total cases managed by CIRM. They reached $12 \%$ in the period of 1982-1984, this can be explained by a universal surge in urethritis and genital herpes. During the 


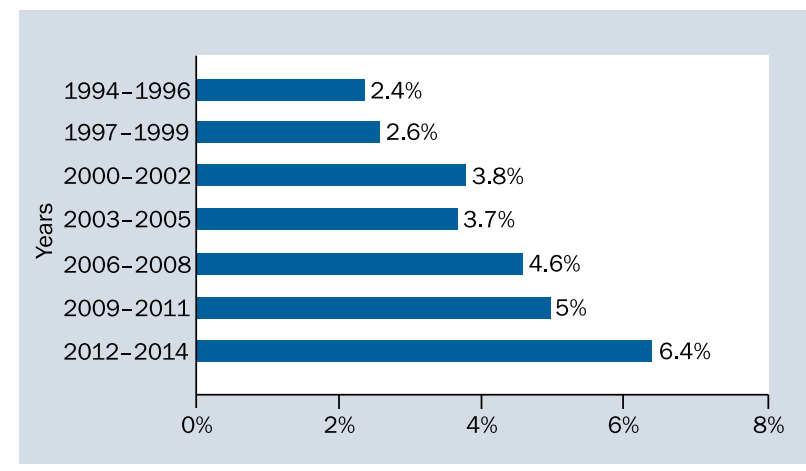

Figure 8. Diseases of the musculo-skeletal system assisted by CIRM from 1994 to 2014. Data are expressed as the percentage of the total cases assisted by the Centre in the years of observation

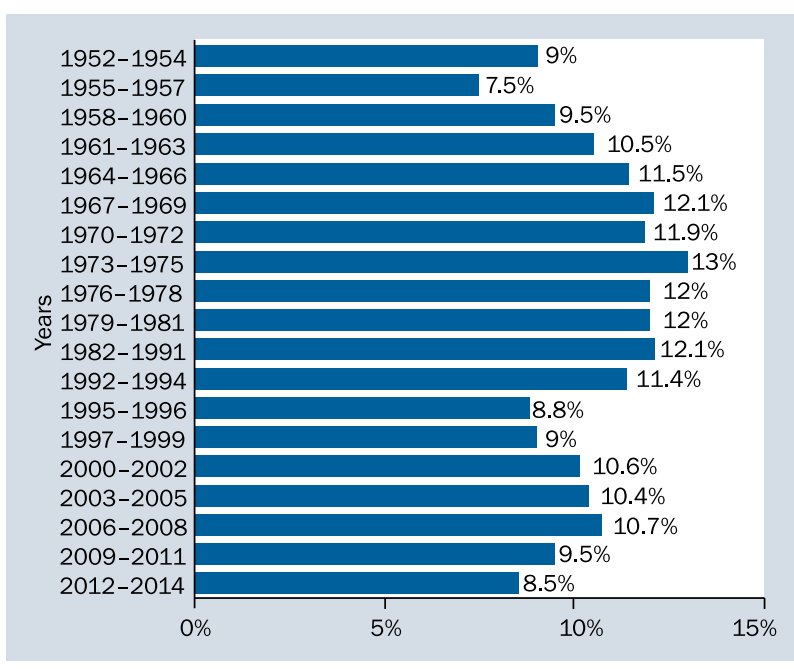

Figure 9. Diseases of the genitourinary system assisted by CIRM from 1952 to 2014. Data are expressed as the percentage of the total cases assisted by the Centre in the years of observation

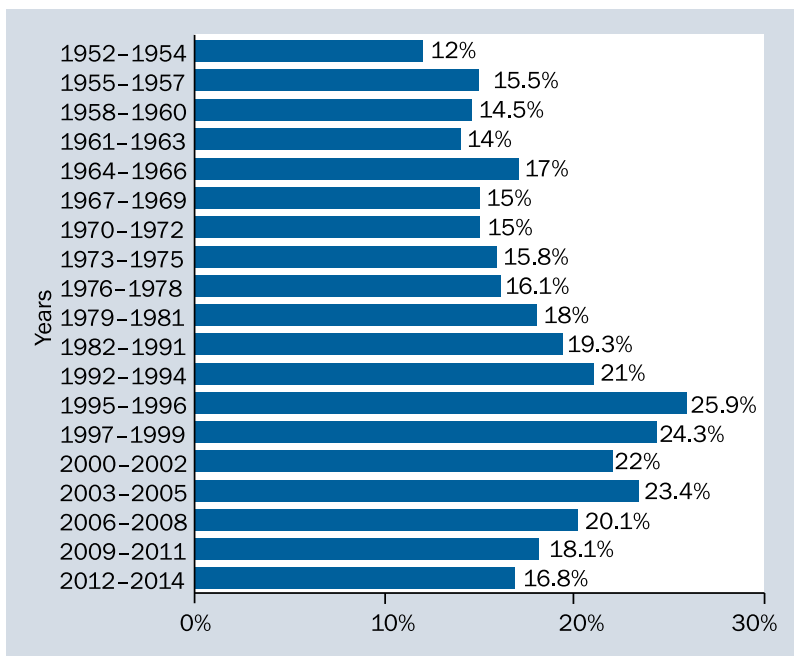

Figure 10. Cases of injury, poisoning and certain other consequences of external causes assisted by CIRM from 1952 to 2014. Data are expressed as the percentage of the total cases assisted by the Centre in the years of observation period of 1992-1994 there was a slight decrease and these cases went down to $11.4 \%$, of all the cases managed. From 1995-2004 the diseases of the genitourinary system went down to $10 \%$ but still represented the third most commonly treated disease on board. In 2014 they remained at $8.5 \%$ (Fig. 9).

Injury, poisoning and certain other consequences of external causes. Occupational injuries have plagued seafarers from antiquity and represent a major portion of all reported cases to CIRM. From 1952 (12\%) until 2014 (17\%) these occupational injuries have accounted from a high of $23 \%$ (1995-2004) to a low of 15\% from 1982-1984 (Fig. 10).

The topic of accidents on board of merchant ships, their causes and how to prevent these events was extensively investigated by CIRM $[17,18]$. The human factors are the prevalent cause of accidents on board ships [17, 18] and this has been consistently reported in the literature [19]. Campaigns for preventing accidents on board ships are also regularly proposed by international organisations such as International Labour Office (ILO) [20] as well as by CIRM [21] technology and education could contribute remarkably to reduce the incidence of accidents on board ships.

\section{DISCUSSION}

Before the 90s communication was a major problem, it was usually very slow but in the last two decades with great advancements in telecommunication technologies and the advent of satellites and internet, things have changed for the better [1, 2, 4, 7]. Today, telecommunications technology allows connectivity in real time with TMAS to ships, and there is also an increase in awareness about the need for addressing of health problems. This change should also make us reflect on how to organise services of maritime telemedical care, operating procedures more efficiently, to reduce the amount of time taken between a request and response. In short, technology speeds up everything, allows the centre to increase potential, but we also need to consider and adapt our pace to this changing scenario.

In 1980, in general, a message from the China Sea to Rome took no less than 8-10 $\mathrm{h}$ and it had to pass through a sluggish terrestrial telecommunications system supporting maritime communication, at the time [1, 2, 4, 7]. Today's satellite networks are communicating in real time, technological advancements improves both the quality of our communications and our service. CIRM is always striving to update its services continuously. These efforts appear to be bearing fruit, given that the number of requests for assistance and, of tele-consultations have increased significantly. During the period of from 1995-2004 CIRM saw a remarkable increase in both capacity and number of calls of assistance from ships. As technology became more efficient, CIRM was able to assist more sailors than ever. 
In the past, probably due to possible telecommunication problems, recommendations on medical assistance at sea did not emphasize the role of radio medical advice. The predominant view was "try to help yourself and in case of difficulties ask for radiomedical advice" [22]. Today thanks to technological evolution, communications from ashore to a ship are much easier and this can result in an improvement of medical assistance to people on board seagoing vessels. There is general agreement that medical background of ship captains or officers with medical assistance duties on board is quite limited [23]. Hence, if technology helps to remain connected, it should be use to transmit medical advice in real time.

Telemedicine is the only means by which it is possible to get expert advice at sea. In spite of the technological progress, medical assistance to seafarers has not improved in parallel with advances of medicine or telecommunications. On the contrary, the need to seek medical advice does not occur very often on every ship. Hence, any system developed for maritime telemedicine purposes must be extremely simple for seafarers to access. Still, the systems must preserve the security and integrity of patient data, as well as help document the information exchange that has taken place between the doctor and the medical officer.

Requests for medical assistance from ships to a specialised medical Centre ashore in general continue to follow the same procedure used several decades ago. The treatment and diagnosis process starts with the simple description of the symptoms of the patient narrated by the captain or person in charge of health safety. This description is followed by several questions from the doctor of the telemedical centre to ascertain a presumptive diagnosis, which can lead them to the best treatment of the disease. TMAS doctor can assess a patient in real time, even without physical presence on board, by using digital medical devices that can gather vitals, monitor progress, view external lesions, capture images of skin, ears, eyes and other areas. Availability of digital devices such as these, take telemedicine a step further.

Based on its own experience of assisting more than thousand patients per year on board ships, CIRM has developed a telemedicine cart loaded with high quality peripherals. Peripherals are assembled to guarantee their mobility. Cords, leads, probes, cameras and other such items are integrated and interfaced with a computer, specifically prepared to guarantee the best exchange of information, and the full compatibility of components of the system. This system (Fig. 11) is being installed on board of 50 ships belonging to the CMA Shipping Company in Marseille. These ships will be the first in the world to be equipped with a fully functional telemedicine system allowing significant improvement of the quality of medical care that can be delivered on board.
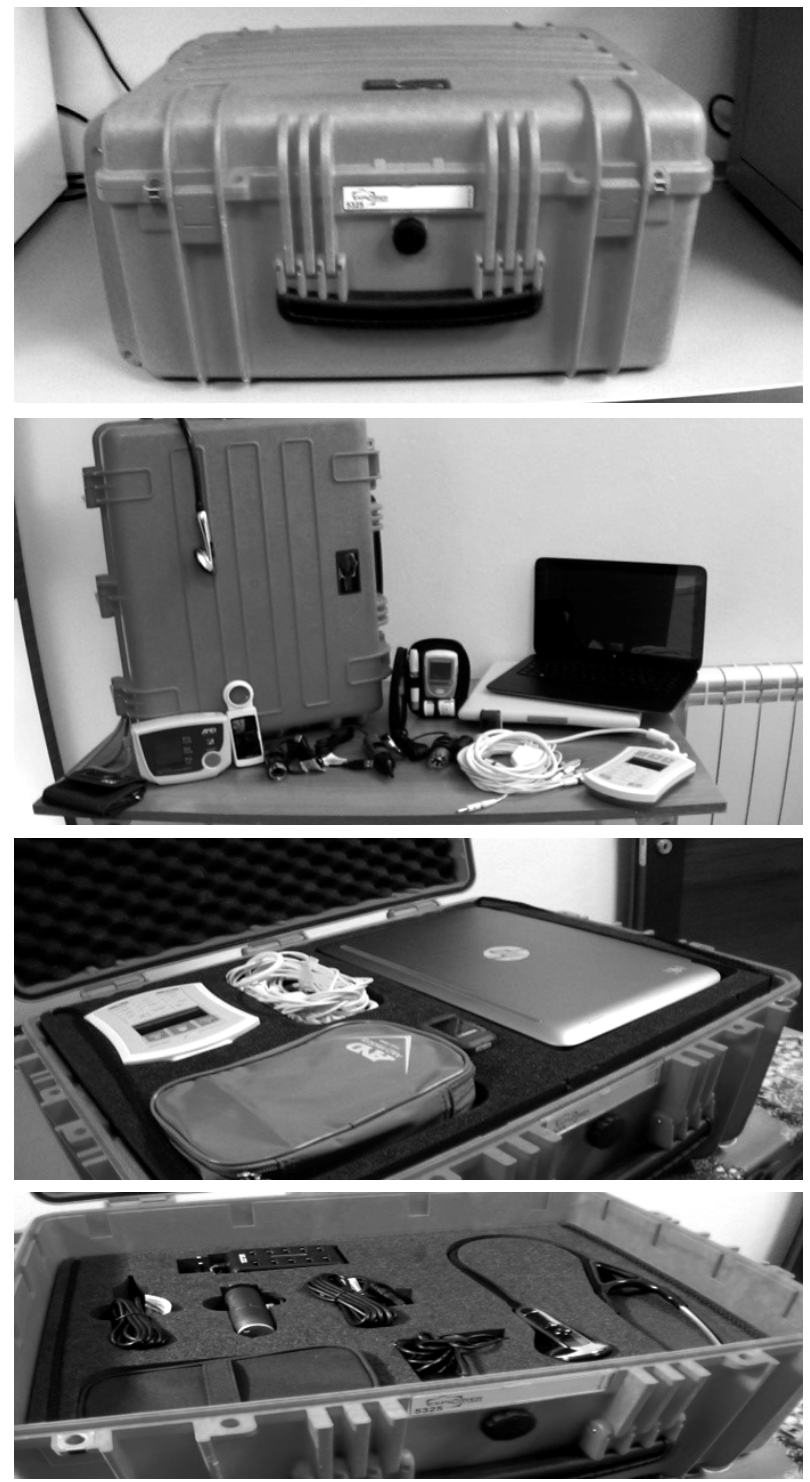

Figure 11. Telemedicine case already installed or being installed in 2015 on board of 50 ships belonging to the French company CMA Ships in Marseille. The case contains an artificial intelligence system for helping to prepare a more precise request for medical advice [24] and the telemedical devices listed below: infrared thermometer, high quality photocamera, electronic phonendoscope, blood pressure monitor, 12 derivations electrocardiogram, spirometer and SPO2, glucometer

\section{CONCLUSIONS}

International Radio Medical Centre is a centre of medical excellence and has provided medical assistance to more remotely located patients on sea vessels than any other organisation in the world. 81,016 patients have been assisted so far by CIRM during the course of 80 years along with more than 500,000 requests for medical assistance. These are exciting times for CIRM as the speed and ease of communications continues to get better with time. Apart from the traditional medical services, the cen- 
tre has now expanded its services to include assessment of stress on board merchant ships [25] and an increased involvement in training and education for seafarers which has already commenced. The future looks bright for CIRM to advance its goal to provide effective health services to remote patients.

\section{ACKNOWLEDGEMENTS}

Special thanks go to the Presidents and to the Members of the Board Trustees of CIRM that in 80 years have guided the Centre, sailing not always in tranquil seas. The CIRM is also particularly grateful to all the doctors who over the years cared with dedication the thousands of seafarers assisted by the Centre. The results achieved in 80 years of activity would not have been possible without the commitment of medical consultants, the telemedicine assistants and administrative and technical support personnel who collaborated with the Centre. The continuous support and help of the Italian Ministry of Infrastructure and Transport (Directorate General for the supervision of port authorities, port facilities and maritime transport and inland waterways) to the activity of CIRM is gratefully acknowledged. Special thanks to the Director General Dr Enrico M. Puja for the continuous attention and commitment on the side of the CIRM in times of trouble. CIRM is also indebted to the society telemedware (Ferrara, Italy) for the development of the telemedicine case described in this paper. Graphic assistance of Mr Vincenzo Del Regno in preparing figures of this manuscript is also gratefully acknowledged.

\section{REFERENCES}

1. Rizzo N, Amenta F. I Cinquanta Anni del Centro Internazionale Radio Medico (Italian). CIRM, Rome 1985.

2. Amenta F, Dauri A, Rizzo N. Organization and activities of the International Radio Medical Centre (CIRM). J Telemed Telecare 1996; 2: 125-131.

3. Goethe WHG, Watson EN, Jones DT eds. Handbook of Nautical Medicine. Springer-Verlag Berlin, Heidelberg 1984.

4. Amenta F. I Sessanta Anni del Centro Internazionale Radio Medico (Italian). CIRM, Rome 1995.

5. Amenta F, Dauri A, Rizzo N. Telemedicine and medical care to ships without a doctor on board. J Telemed Telecare 1998; 4 (suppl. 1): 44-45.

6. International Maritime Organization (IMO). Medical Assistance at Sea. Circular MSC/Circ.960. IMO, London, 2000

7. Rizzo N, Camerucci S. Telemedicine in radio medical assistance for seafarers: new developments and technical evolutions. In: Bracale M, Denoth F eds. Proceedings of the Health Telematics '95. CNR, Pisa 1995; pp. 209-212.
8. World Health Organization. International Statistical Classification of Diseases and Related Health Problems $10^{\text {th }}$ Revision. WHO, Geneva 1994.

9. D. Lgs. 27 luglio 1999, n. 271. Adeguamento della normativa sulla sicurezza e salute dei lavoratori marittimi a bordo delle navi mercantili da pesca nazionali, a norma della L. 31 dicembre 1998, n. 485 (Italian). Italian Republic Official Gazette 19 August 1999, No. 185.

10. Amenta F, Dauri A. Activities of the International Radio Medical Centre (CIRM) in Rome during the last five years (1996-2000). Int Maritime Health 2001; 52: 68-73.

11. Westlund K, Attvall S, Nilsson R, Jensen OC. Telemedical Maritime Assistance Service (TMAS) to Swedish merchant and passengers ships 1997-2012. Int Maritime Health 2016; 67: 24-30

12. Vallé B, Camelot D, Bounes V et al. Cardiovascular diseases and electrocardiogram teletransmission aboard ships: the French TMAS experience. Int Marit Health 2010; 62: 129-136.

13. World Health Organization. International Statistical Classification of Diseases and Related Health Problems 9th Revision. WHO, Geneva 1975.

14. Grappasonni I, Petrelli F, Amenta F. Deaths on board ships assisted by the Centro Internazionale Radio-Medico in the last 25 years. Travel Med Infect Dis 2012; 10: 186-191.

15. Mahdi SS, Mancini M, Sibilio F, Amenta F. Research questionnaire on perception of seafarers about oral hygiene and oral dietary habits. World J Dent 2015; 6: 1-4.

16. Mahdi S, Sibilio F, Amenta F. Dental hygiene habits and oral health status of seafarers. Int Marit Health 2016; 67: 9-13.

17. Rizzo N, Amenta F. Accidents on board merchant ships. In: Cullen J, Siegrist J eds. Breakdown in Human Adaptation to Stress. Nijhoff, Boston 1984; pp. 469-483.

18. Napoleone P. Accidents on board merchant ships. Suggestions based on Centro Internazionale Radio Medico (CIRM) experience. Int Marit Health 2016; 67: 21-23.

19. Hetherington C, Flin R, Mearns K. Safety in shipping: the human element. J Safety Res 2006; 37: 401-411.

20. International Labour Office. Accident Prevention on Board Ship at Sea and in Port. An ILO code of practice. 2nd Ed. International Labour Office, Geneva 1996.

21. Amenta F, Sibilio F. Buone Pratiche in caso di Infortuni a Bordo delle Navi (Italian). CIRM, Rome 2014.

22. International Labour Organization. Medical Advice at Sea Recommendation No. 106. ILO, Geneva 1958.

23. Ricci G, Pirillo I, Rinuncini C, Amenta F. Medical assistance at the sea: legal and medico-legal problems. Int Marit Health 2014; 65: 205-209.

24. Carletti G, Giuliodori P, Di Pietri V, Peretti A, Amenta F. An ontology-based consultation system to support medical care on board seagoing vessels. Int Marit Health 2016; 67: 14-20.

25. Carotenuto A, Fasanaro A, Molino I, Sibilio F, Saturnino A, Traini E. The Psychological General Well-Being Index (PGWBI) for assessing stress of seafarers on board merchant ships. Int Marit Health 2013; 64: $215-220$. 